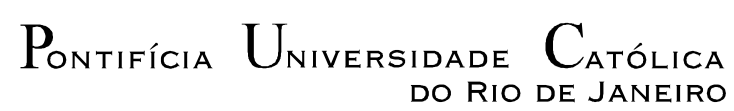

DO RIO DE JANEIRO

Carlos Frederico Vanderlinde Tarrisse da Fontoura

\author{
Avaliação de Projeto de Investimento em Usina \\ Termelétrica à Capim-Elefante: \\ Uma Abordagem Pela Teoria de Opções Reais
}

Dissertação de Mestrado

Dissertação apresentada ao Programa de Pósgraduação em Administração de Empresas da PUCRio como requisito parcial para obtenção do título de Mestre em Administração de Empresas.

Orientador: Prof. Luiz Eduardo Teixeira Brandão

Rio de Janeiro

Abril de 2011 


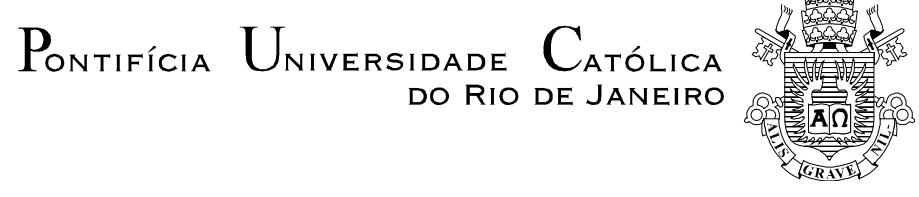

Carlos Frederico Vanderlinde Tarrisse da Fontoura

\section{Avaliação de Projeto de Investimento em Usina \\ Termelétrica à Capim-Elefante: \\ Uma Abordagem Pela Teoria de Opções Reais}

Dissertação apresentada como requisito parcial para obtenção do grau de Mestre pelo Programa de PósGraduação em Administração de Empresas da PUCRio. Aprovada pela Comissão Examinadora abaixo assinada.

Prof. Luiz Eduardo Teixeira Brandão

Orientador

Departamento de Administração - PUC-Rio

Prof. Leonardo Lima Gomes

Departamento de Administração - PUC-Rio

Prof. Carlos de Lamare Bastian Pinto Universidade do Grande Rio - UNIGRANRIO

Prof. Marco Antonio Guimarães Dias

Petróleo Brasileiro S.A. - Petrobras

Prof. Monica Herz

Coordenador(a) Setorial do Centro de Ciências Sociais - PUC-Rio

Rio de Janeiro, 05 de abril de 2011 
Todos os direitos reservados. É proibida a reprodução total ou parcial do trabalho sem autorização da universidade, do autor e do orientador.

\section{Carlos Frederico Vanderlinde Tarrisse da \\ Fontoura}

Graduou-se em Engenharia Elétrica com ênfase em Telecomunicações pelo Centro Federal de Educação Tecnológica Celso Suckow da Fonseca (CEFET/RJ), em 2006. Em 2009, ingressou no Programa de Pós-Graduação em Administração de Empresas da PUC-Rio, para obtenção do título de Mestre.

Atualmente trabalha no setor de Tecnologia de Informação e Telecomunicações da Petróleo Brasileiro S.A. - Petrobras, mas especificamente na área de operação e manutenção dos serviços de telecomunicações.

Ficha Catalográfica

Fontoura, Carlos Frederico Vanderlinde Tarrisse da

Avaliação de projeto de investimento em usina termelétrica à capim-elefante : uma abordagem pela teoria de opções reais / Carlos Frederico Vanderlinde Tarrisse da Fontoura ; orientador: Luiz Eduardo Teixeira Brandão. - 2011.

86 f.: il. ; $30 \mathrm{~cm}$

Dissertação (mestrado) - Pontifícia Universidade Católica do Rio de Janeiro, Departamento de Administração, 2011.

Inclui bibliografia

1. Administração - Teses. 2. Usina termelétrica. 3. Biomassa. 4. Capim-Elefante. 5. Opções reais. 6. Modelo de reversão à média com saltos. I. Brandão, Luiz Eduardo Teixeira. II. Pontifícia Universidade Católica do Rio de Janeiro. Departamento de Administração. III. Título. 
À minha esposa, cujo amor me dá forças para atingir meus objetivos. 


\section{Agradecimentos}

Agradeço primeiramente a Deus e a Virgem Maria pelo amor incondicional com o qual me acolhem e por serem o pilar que me suporta em todos os momentos.

À minha esposa, Yuna Fontoura, por ter sido a grande incentivadora do meu ingresso neste mestrado e pela paciência e compreensão ao longo deste período.

Aos meus pais, Carlos Eduardo Fontoura e Thelma Fontoura, pelo amor, suporte e compreensão dos longos períodos de ausência e por terem me propiciado uma base sólida de conhecimento que muito contribuiu para o desenvolvimento deste trabalho.

Aos meus sogros, Erington Reis e Maria Alzenir Reis, por me acolherem como um filho e estarem disponíveis sempre que foi necessário.

Ao professor Luiz Brandão cujo apoio e orientação foram fundamentais para a elaboração desta dissertação.

Ao professor Leonardo Gomes, por ter instigado o meu interesse nos setores de energia elétrica e de biomassa.

Aos meus superiores na Petrobras Rosiane Aragão e Firmo do Couto Filho, pelo incentivo e por me permitirem a flexibilidade de horário necessária para cursar o mestrado.

À Pontifícia Universidade Católica do Rio de Janeiro, mais especificamente ao IAG, por oferecer um curso de mestrado acadêmico fora do horário comercial, atendendo assim aos que não podem se distanciar do trabalho para cursá-lo. 


\section{Resumo}

Fontoura, Carlos Frederico Vanderlinde Tarrisse da; Brandão, Luiz Eduardo Teixeira. Avaliação de Projeto de Investimento em Usina Termelétrica à Capim-Elefante: Uma Abordagem pela Teoria de Opções Reais. Rio de Janeiro, 2011. 86p. Dissertação de Mestrado - Departamento de Administração, Pontifícia Universidade Católica do Rio de Janeiro.

O Brasil é um país cuja matriz elétrica é fortemente dependente da geração por usinas hidrelétricas. Dentro desse cenário, a utilização de usinas termelétricas a biomassa representa uma alternativa vantajosa, pois associa a diversificação da matriz energética brasileira à utilização de fontes renováveis, além de não ser poluidora como suas contrapartes movidas a combustíveis fósseis não renováveis como óleo combustível e gás. Este estudo teve como objetivo realizar a avaliação econômica de um projeto de investimento em uma usina termelétrica a biomassa, adotando estratégias com e sem flexibilidades gerenciais e operacionais, de forma a identificar a metodologia de avaliação mais adequada ao projeto em questão. $\mathrm{Na}$ estratégia sem flexibilidade foi adotado o método do fluxo de caixa descontado. Já nas estratégias com incertezas e flexibilidades, foram incorporadas as incertezas referentes ao mercado de energia elétrica e as flexibilidades relacionadas à possibilidade da usina comercializar a energia elétrica gerada integral ou parcialmente nos mercados de longo ou curto prazo. Além disso, há a possibilidade de instalação de uma usina de briquetagem, que permitiria a planta comercializar energia elétrica no mercado de curto prazo ou biomassa em formato de briquetes, dependendo do que for economicamente mais interessante. Os resultados obtidos indicam que a existência de incertezas e flexibilidades gerenciais aumenta o valor do projeto e reduzem significativamente o risco de insucesso do mesmo, o que reforça a idéia de que a avaliação por opções reais, apesar de mais complexa, pode ser mais adequada para determinar o real valor do projeto.

\section{Palavras-chave}

Usina Termelétrica; Biomassa; Capim-Elefante; Opções Reais; Modelo de Reversão à Média com Saltos 


\section{Abstract}

Fontoura, Carlos Frederico Vanderlinde Tarrisse da; Brandão, Luiz Eduardo Teixeira (Advisor). Evaluating an Elephant Grass Power Plant Investment Project Using the Real Options Theory Approach. Rio de Janeiro, 2011. 86p. MSc. Dissertation - Departamento de Administração, Pontifícia Universidade Católica do Rio de Janeiro.

Brazil is a country whose energy matrix is strongly dependent on generation by hydropower plants. Within this scenario, the use of biomass power plants represents an attractive alternative, since it associates the diversification of the Brazilian energy matrix with the use of renewable sources, and is not as polluting as their counterparts moved to non-renewable fossil fuels such as oil and gas. This study aimed to conduct the economic evaluation of an investment in a project of a biomass power plant, considering strategies with and without managerial and operational flexibilities, in order to identify the best methodology for evaluating the project in question. In the strategy without flexibilities, the discounted cash flow method was adopted. In the strategies with uncertainties and flexibilities, the uncertainties related to the electricity market and flexibilities related to the possibility of selling the electricity generated in the long or short term markets were incorporated into the analysis. Moreover, there is the possibility of installing a briquetting plant, which would allow the plant to choose between selling electricity in the short term market or briquettes, whichever is more economically interesting. The results indicate that the existence of uncertainties and managerial flexibilities increases the value of the project and reduces significantly the risk of failure, which reinforces the idea that the evaluation with real options, though more complex, can be more appropriate to determine the actual value of the project.

\section{Keywords}

Power Plant; Biomass; Elephant Grass; Real options; Mean Reversion with Jumps Model 


\section{Sumário}

1. Introdução

2. Avaliação de projetos em ambiente de incerteza 16

2.1. Teoria de Opções Reais 17

2.2. Tipos de Opções Reais 19

2.3. Modelagem de incertezas por meio de processos estocásticos 20

3. O Setor Elétrico Brasileiro (SEB) 23

3.1. Comercialização de energia no SEB 24

3.2. Contratos de Compra de Energia no Ambiente Livre 25

3.3. Energia incentivada 26

3.4. Os contratos de comercialização de energia incentivada 27

3.5. Descontos na TUSD/TUST pela comercialização de energia incentivada 28

3.6. Preço de liquidação das diferenças 28

4. Biomassa 30

4.1. Biomassa para fins energéticos 31

4.2. Fontes de Biomassa energética 35

4.3. Capim-elefante 35

4.4. Capim-elefante para fins energéticos 37

4.5. Capim-elefante para produção de energia elétrica 38

4.6. Capim-elefante para produção de briquetes 38

5. Modelagem do Preço de Liquidação das Diferenças 40

5.1. Modelos de reversão à média 42

5.2. Modelos de reversão à média com saltos 44

5.3. O modelo de reversão à média com saltos de Clewlow, Strickland e Kaminski (2000) 45

5.3.1. Definição do modelo 45 
5.3.3. Processos neutros ao risco 47

5.3.4. Estimação dos parâmetros 48

6. Aplicação em uma usina termelétrica a biomassa fictícia 51

6.1. Metodologia 51

6.2. Modelagem das receitas líquidas provenientes da venda dos subprodutos da usina $\quad 52$

6.2.1. Receita líquida proveniente da venda de energia em contrato de longo prazo (RLelp) 53

6.2.2. Receita líquida proveniente da venda de briquetes (RLbriq) 53

6.2.3. Receita líquida proveniente da venda de energia no mercado de curto prazo (RLspot) 54

6.3. Fluxo de caixa da estratégia 1

6.4. Fluxo de caixa da estratégia 2

6.5. Fluxo de caixa da estratégia $3 \quad 57$

6.6. Coleta de dados 59

6.6.1. Variáveis associadas ao investimento e custos fixos da usina termelétrica 59

6.6.1.1. Taxa do dólar (PTAX) 59

6.6.1.2. Custo de instalação e custo operacional fixo (sem briquetagem) $\quad 59$

6.6.1.3. Custo de instalação e custo operacional fixo da unidade de briquetagem 60

6.6.1.4. Custo da terra nua 60

6.6.1.5. Produtividade do capim-elefante 61

6.6.1.6. Tamanho da área de plantio 61

6.6.1.7. Custos de formação e manutenção da área de plantio e colheita, picagem, secagem, compactação e transporte da biomassa 62

6.6.2. Variáveis associadas à receita líquida proveniente da venda de briquetes 62

6.6.2.1. Valor da tonelada de briquetes no mercado atacadista 63

6.6.2.2. Volume semanal de briquetes vendidos 63 
6.6.2.3. Custos de comercialização dos briquetes

6.6.2.4. Impostos diretos incidentes sobre a comercialização de briquetes

6.6.3. Variáveis associadas à receita líquida proveniente da venda de energia elétrica

64

6.6.3.1. Preço da energia elétrica comercializada em contratos de longo prazo

64

6.6.3.2. Custo variável da produção de energia elétrica e TUST

65

6.6.3.3. Impostos diretos incidentes sobre a comercialização de energia elétrica

65

6.6.3.4. Preço da energia elétrica comercializada no mercado de curto prazo

65

6.6.3.4.1. Valor do ágio $\quad 65$

6.6.3.4.2. Valor do PLD 66

6.6.3.4.3. Modelagem do PLD utilizando o modelo de reversão à média com saltos de Clewlow, Strickland e Kaminski (2000) modificado 67

7. Resultados 70

7.1. Estratégia 1 71

7.2. Estratégia $2 \quad 72$

7.3. Estratégia $3 \quad 74$

7.4. Síntese dos resultados 75

8. Conclusões e Recomendações 77

8.1. Conclusões 77

8.2. Limitações metodológicas e sugestões para trabalhos futuros 78

9. Referências 80 


\section{Lista de figuras}

Figura 1 - Diagrama esquemático dos processos de conversão energética da biomassa 32

Figura 2 - Série semanal deflacionada do PLD 67

Figura 3 - Simulação PLD sem limites $\quad 69$

Figura 4 - Simulação PLD com limites $\quad 69$

Figura 5 - Distribuição de probabilidade do VPL da estratégia $2 \quad 73$

Figura 6 - Distribuição de probabilidade do VPL da estratégia 3 


\section{Lista de tabelas}

Tabela 1 - Comparação Opção Financeira x Opção Real 18

Tabela 2 - Tipos de Opções Reais 19

Tabela 3 - Processos estocásticos mais usuais $\quad 21$

Tabela 4 - Usinas termelétricas a biomassa em operação em 2008 por insumo 32

Tabela 5 - Tecnologias de geração térmica a biomassa 33

Tabela 6 - Capacidade instalada com fonte de geração em biomassa 34

Tabela 7 - Fontes de biomassa e suas vantagens e desvantagens 35

Tabela 8 - Características agronômicas do capim-elefante 36

Tabela 9 - Comparação de produtividade de energia por hectare 36

Tabela 10 - Resultados da regressão da série do PLD 41

Tabela 11 - Saltos identificados com filtro recursivo 49

Tabela 12 - Preço médio da terra nua em algumas regiões de SP em R $\$ /$ ha 61

Tabela 13 - Produtividade do capim-elefante $\quad 61$

Tabela 14- Custos de formação e manutenção da área de plantio, colheita, picagem, secagem, compactação e transporte 62

Tabela 15 - Dados briquetagem 63

Tabela 16 - Parâmetros da simulação $\quad 68$

Tabela 17 - Valores das variáveis da estratégia $1 \quad 72$

Tabela 18 - Valores das variáveis da estratégia $2 \quad 73$

Tabela 19 - Valores das variáveis da estratégia $3 \quad 74$

Tabela 20 - Comparativo do VPL médio das três estratégias 76

Tabela 21 - Valor das opções presentes no projeto 76 